\title{
Improving the management of midnight data to enhance evidence-based decision making.
}

A. P. Sandanayake ${ }^{(i)}$, S. C. Wickramasinghe

\section{ABSTRACT}

Introduction: Hospitals collect and store massive amounts of data. Developing better 'Information Systems' to manage these data more efficiently had been a challenge during the past decades, and automation was considered by many as the way forward.

Method: An interventional project with predominantly qualitative methodology was carried out to implement and then assess a manual and computer-based intervention for management of midnight data at Base Hospital, Horana. Key Informant Interviews, Focus Group Discussions, and document reviews were the key components of the qualitative arm of the study. A satisfaction survey was subsequently conducted among the nursing staff, and selected indicator values were measured pre and post-implementation.

Results: Following the pre-interventional analysis, the modified data management system was introduced to address the gaps in the system. The post-interventional analysis revealed that the modified system has better and user-friendly collecting, reporting and analysing tools, enhanced data dissemination capabilities and favourable outcome with the inbuilt system to identify data errors. Satisfaction among the nursing staff demonstrated visible improvement.

Conclusion: The study recommends a gradual introduction of process modification and automation of the midnight data management system at Base Hospital Horana.

Keywords: Midnight Report, Hospital Information Systems, Evidence-Based Decision Making

\section{INTRODUCTION}

A large amount of data is collected in hospitals each day(1). During the past decades, demand for 'Information Systems' which are better equipped to collect, process and analyse reliable data has risen rapidly(2). In 1991, a report from the General Accounting Office of United States stated that automated records could significantly enhance patient management by providing more accurate, higher quality, readily accessible information to support evidence-based decision-making(3).

High cost, underdeveloped technology, difficulties in adapting to change and security concerns are key challenges to overcome when developing information systems. Balaraman and Kosalram (2013) mentioned support from the top, introduction of userfriendly systems and training as key ingredients for success ${ }^{(4)}$.

In Sri Lanka, the system of medical record keeping is predominantly paper-based, placing heavy pressure on healthcare workers ${ }^{(5)}$. Even though there were isolated projects where process automation was integrated, no large-scale e-Health projects had been implemented so far in the country ${ }^{(6)}$. In 2015, a Health Information Management System (HIMS) was implemented in the Outpatient Department at Base Hospital Horana (BHH). The plan was to expand the automation gradually, to enhance hospital data management. However, the process has been stalled since its inception. As a result, a significant proportion of generated data, including Midnight Data, lies dormant in their raw form, unused(7). a Ministry of Health Sri Lanka

Correspondence to: A. P. Sandanayake, Ministry of Health, Sri Lanka

bantu179@hotmail.com

ORCID ID:

https://orcid.org/00000001-9248-8637

Article history:

Received 29 May 2020

Revised 07 July 2020

Accepted 15 July 2020

Published 31 October 2020

DOI:

http://doi.org/10.4038/sljb mi.v11i1.8092

(C) This is an open access article licensed under a Creative Commons Attribution-Share Alike 4.0 International License (CC BYSA 4.0), which permits unrestricted use, distribution and reproduction in any medium, provided the original author and source are attributed and materials are shared under the same license.

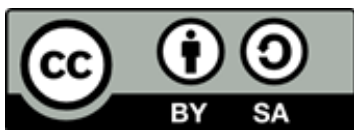




\section{OBJECTIVES}

The objective of the study was to implement and then assess an intervention for management of hospital Midnight Data to enhance evidence-based decision making on patient care services at Base Hospitals, Horana (BHH). The intervention comprises manual and computer-based process modification and automation.

\section{METHODOLOGY}

The project followed an interventional design. The limited number and diverse nature of individuals involved in the process and the specialised nature of each individual's responsibility demanded a predominantly qualitative methodology.

Triangulation was used, a technique used in qualitative studies which is a proven and efficient design. Aim of achieving saturation point was used as a method of ensuring collection of complete data. Framework thematic analysis ${ }^{(8)}$ and Bowens' method of document review were used for data analysis ${ }^{(9)}$.

Purposively selected interviewees were included in the Key Informant Interviews (KII) and Focus Group Discussions (FGD). The saturation level determined the sample size for each phase of the study.

The project was conducted in three phases;

\section{Phase 1}

A pre-interventional study was conducted to describe the existing process of Midnight Data management and identify gaps in the system. A total of nine KII and two FGD were conducted with individuals involved in the process.

\section{Phase 2}

A hybrid technique was adopted where a manual and computer-based Data Management System was designed and implemented. Before implementation, discussions were held with the relevant stakeholders, and implementation schedule was agreed upon. Introductory and training sessions were conducted for the relevant officers. New data collecting, reporting and analysing tools were introduced, and the modified process was explained during these sessions.

Through the first two weeks in operation, minor alterations and modifications were made to the system to enhance operability.

\section{Phase 3}

The outcome of the implemented system was assessed to determine its' ability to improve the management of
Midnight Data and to enhance the evidence-based decision-making process.

a) The same individuals interviewed in phase 1 were reinterviewed.

b) A satisfaction survey was conducted among the nursing staff using a self-administered questionnaire. Participants were requested to compare the pre and post-intervention processes.

c) Selected indicators were measured for pre and post comparison.

Ethical Clearance for this study was obtained from the Ethics Review Committee of the Postgraduate Institute of Medicine, University of Colombo, Sri Lanka.

\section{RESULTS}

\section{Phase 1- Pre-Intervention}

\subsection{Current Process}

All inward patients were admitted to the Preliminary Care Unit (PCU) where a Bed Head Ticket (BHT) was issued. As patients progress from admission to discharge, details were entered in several books/ registers (data collecting tools) as illustrated in Figure 1.

Summary data extracted from these books/ registers were used to create two reports.

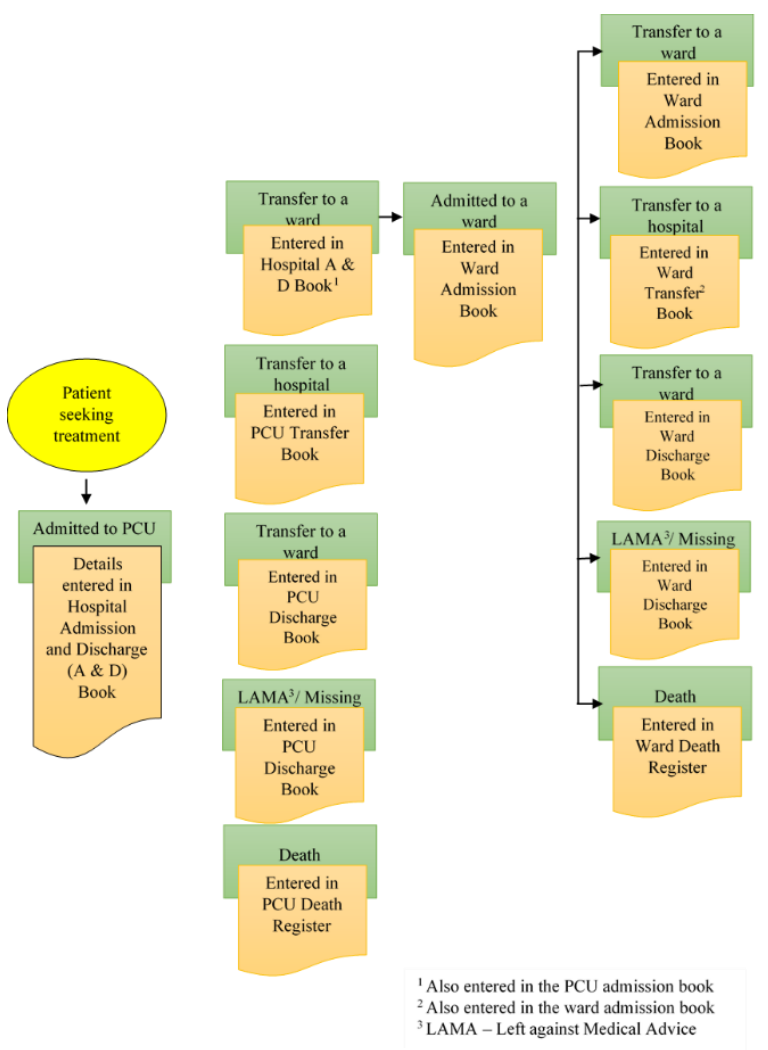

Figure 1: Patients' progress from admission to discharge and process of data collection 
1. Ward/ Unit Midnight Report (MNR)

\section{Hospital Midnight Report}

The process is presented in Figure 2.

Numerical variables collected and reported through this process included: midnight totals of the previous day and today, new admissions, discharges, transfers and patient details extracted from BHTs ('Individual Patient Summaries').

At the end of each month, data from the Hospital MNR were entered into a spreadsheet (Figure 3). It generated monthly totals and daily averages for midnight totals, transfers, admissions, and discharges.

\subsection{Gap Analysis}

Framework based on the analysed KIIs and FGDs generated two themes, six sub-themes and has identified the following system gaps.

1. 'Individual Patient Summaries' were 'too long', and vital information was 'often missing'.

2. Same data were entered in multiple reports

3. Data collecting and reporting formats lacked uniformity

4. Data analysis sheet generated limited information

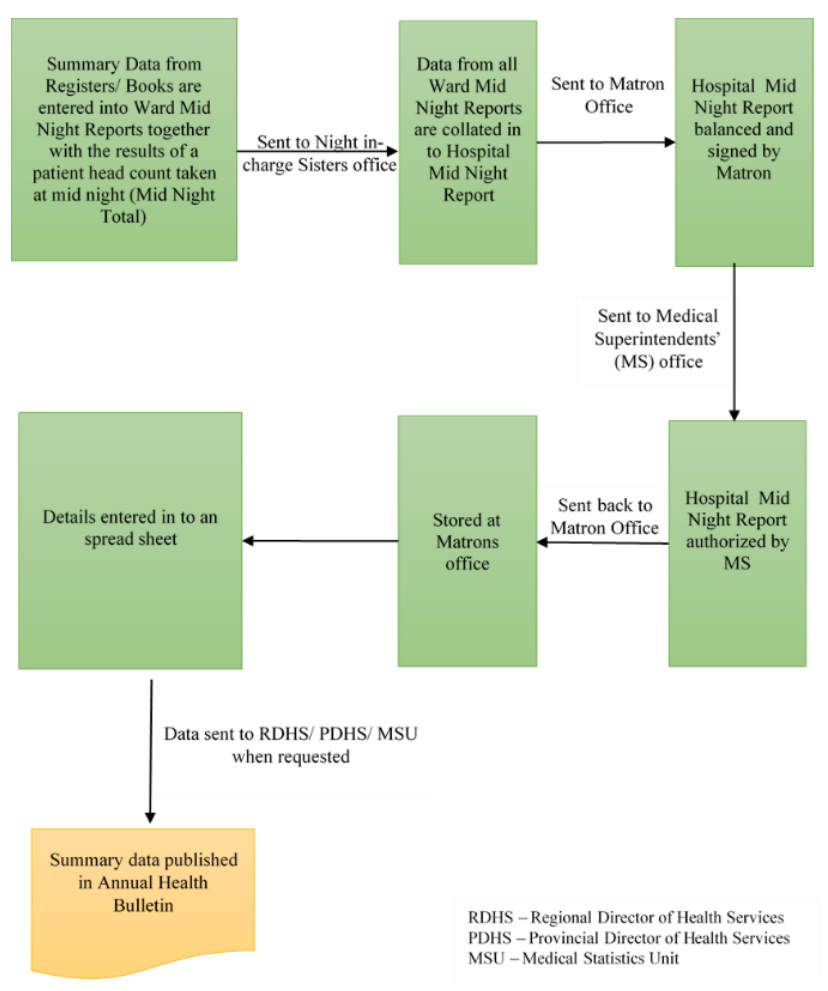

Figure 2: Process of generating MNR and the data flow
5. Data were not regularly dispersed among stakeholders

6. Data were rarely used for decision making

7. Data accuracy was not evaluated

8. Several data items including 'same day discharges', and 'deaths categorised as before and after $48 \mathrm{~h}$ ' were not collected

\section{Phase 2 - Intervention}

\subsection{Step 1}

Existing books/ registers were renamed, and variables were reassigned to ensure uniformity. Previously missing data were included.

\subsection{Step 2}

Two data reporting tools were designed. For numerical data, structured designs were introduced in printed formats with provisions to report previously missing data (Figure 4 \& Figure 5). Similarly, structured, printed designs with designated sections: e.g. Name, Date, BHT,

Presenting Complaint etc. were introduced for 'Individual Patient Summaries' (Figure 6)

\subsection{Step 3}

A new spreadsheet was designed with provisions to analyse data which was not previously analysed. It

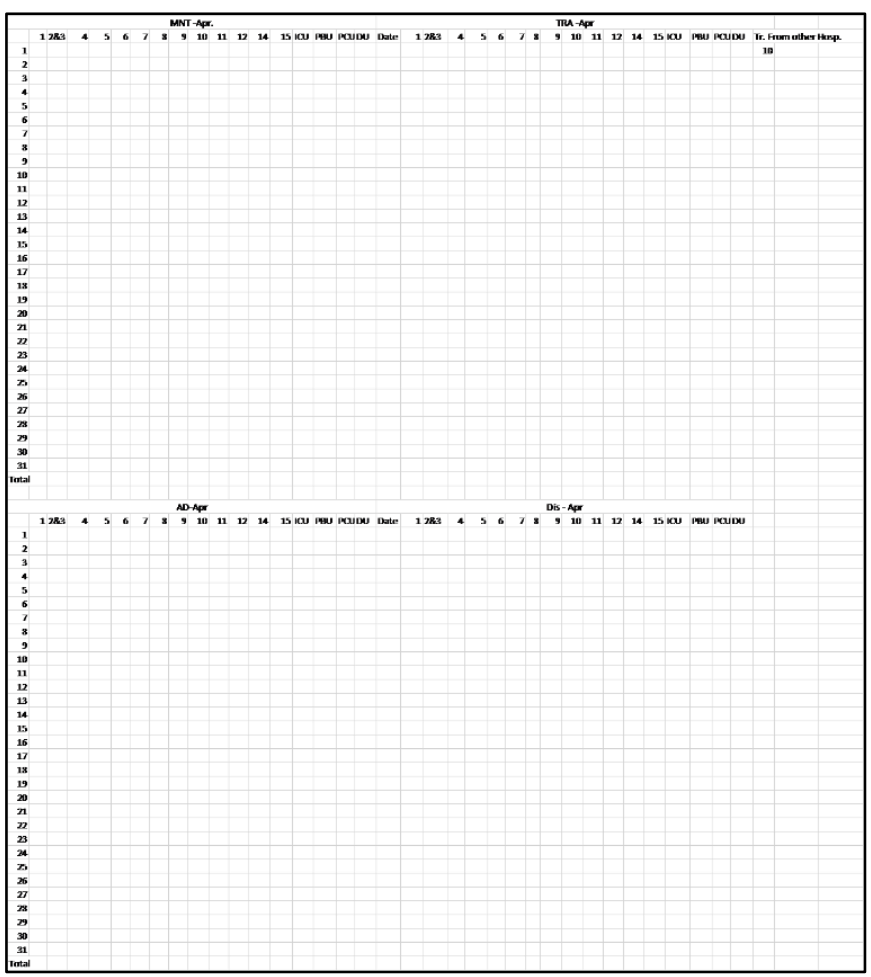

Figure 3: Data analysing tool (spread sheet) currently used by the planning unit 
generated key indicators such as monthly, quarterly sums and averages for all numerical variables, Daily In-Patient Census, Inpatient Service Days, Average Daily Inpatient Census, Average Length of Stay, Inpatient Bed Occupancy Rate, Bed Turnover Rate and Death Rates (Figure 7 \& Figure 8).
Inbuilt features to detect errors included: the ability to auto-generate the number of daily admissions from BHT numbers and compare it with the sum of individual ward admissions, calculate the Midnight Total from the entered data and compare it with the midnight census.

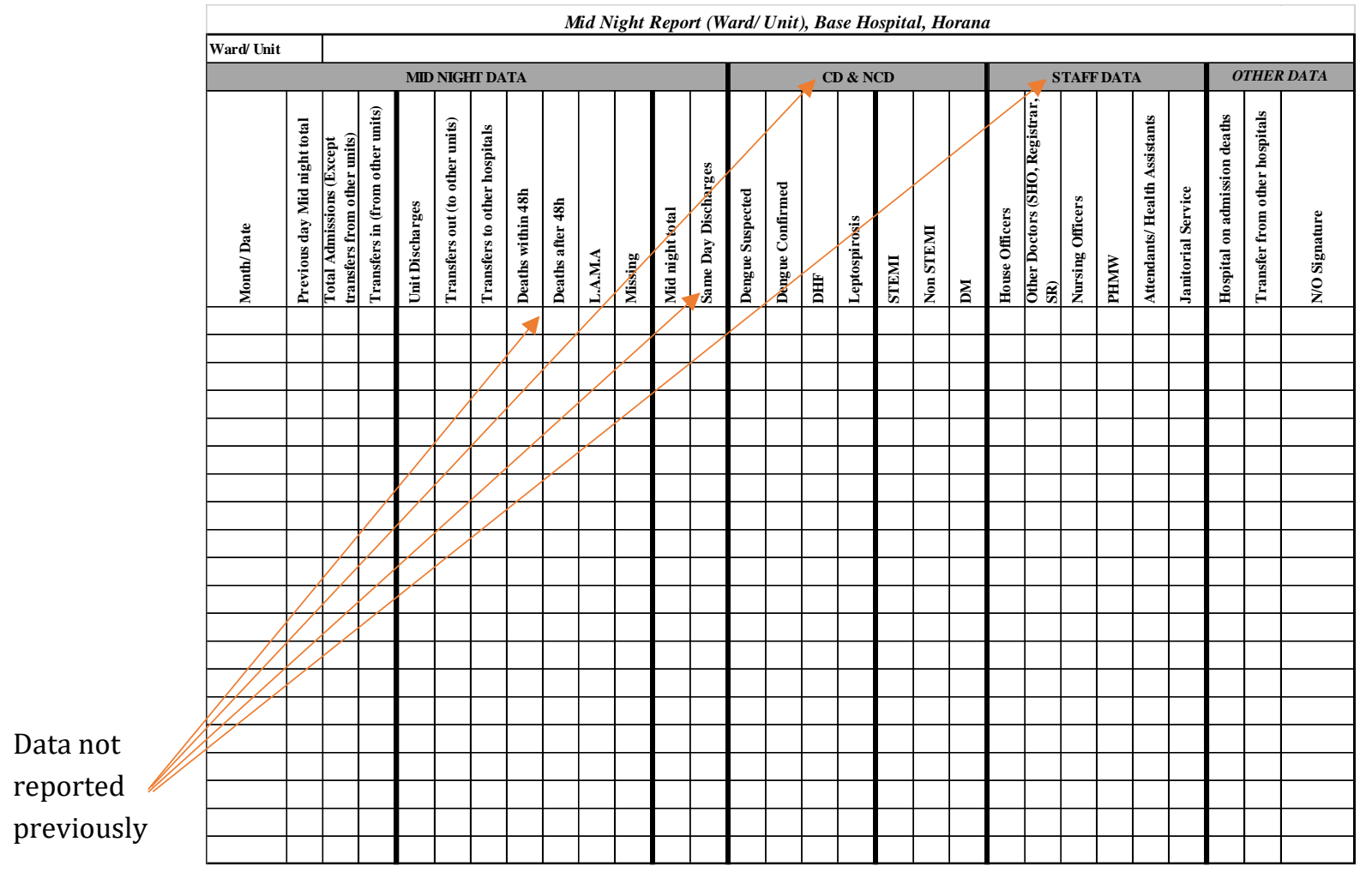

Figure 4: New Ward/ Unit MNR (Numerical Data Section)

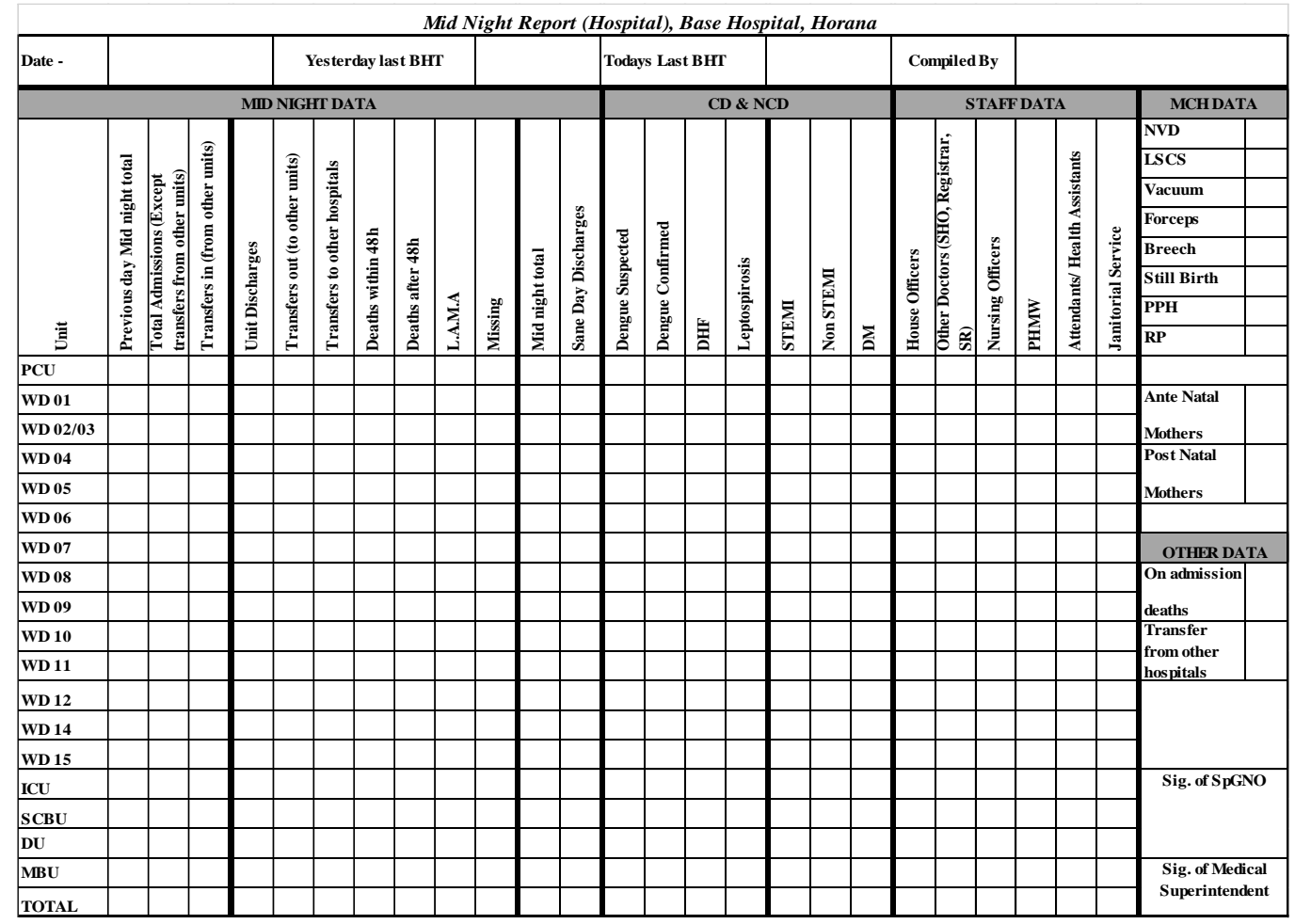

Figure 5: New Hospital MNR (Numerical Data) 


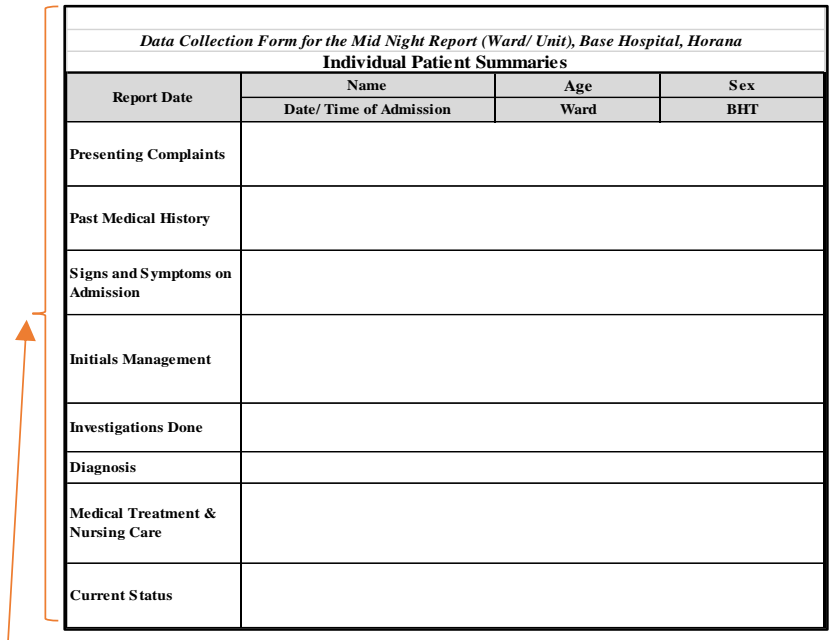

Structured Format Introduced

Figure 6: MNR reporting form for 'Individual Patient Summaries'

In addition, datasheet graphically visualised the admissions, discharges (as bar charts), trends of Communicable Diseases (as line graphs), and other key information as tables.

\subsection{Step 4}

The 'Individual Patient Summaries' written by ward nurses in ward MNRs were attached to the hospital MNR (eliminating duplication). The Midnight Data were entered into the new analysis sheet daily. Data visualisation sheets were presented to the Medical Superintendent, together with the MNR. Summary data were e-mailed to Regional directors' office monthly.

\begin{tabular}{|c|c|c|}
\hline & $\begin{array}{c}\text { Monthly } \\
\text { Total }\end{array}$ & $\begin{array}{l}\text { Per Day } \\
\text { Average }\end{array}$ \\
\hline \multicolumn{3}{|c|}{ Hospital } \\
\hline Total Admissions & 0 & \#DIV/0! \\
\hline Inpatient service days & 0 & \#DIV/0! \\
\hline Total Discharges* & 0 & \#DIV/0! \\
\hline Total transfers from other hospitals & 0 & \#DIV/0! \\
\hline Total transfers to other hospitals & 0 & \#DIV/0! \\
\hline Death within $48 \mathrm{~h}$ & 0 & \#DIV/0! \\
\hline Death after $48 \mathrm{~h}$ & 0 & \#DIV/0! \\
\hline \begin{tabular}{|l} 
Total deaths \\
\end{tabular} & 0 & \#DIV/0! \\
\hline Total LAMA & 0 & \#DIV/0! \\
\hline Total missing & 0 & \#DIV/0! \\
\hline \multicolumn{3}{|l|}{ WD 1} \\
\hline Total Admissions & 0 & \#DIV/0! \\
\hline Inpatient service days & 0 & \#DIV/0! \\
\hline Total Discharges* & 0 & \#DIV/0! \\
\hline Transfer to other hospitals & 0 & \#DIV/0! \\
\hline Death within $48 \mathrm{~h}$ & 0 & \#DIV/0! \\
\hline Death after $48 \mathrm{~h}$ & 0 & \#DIV/0! \\
\hline Total deaths & 0 & \#DIV/0! \\
\hline Total LAMA & 0 & \#DIV/0! \\
\hline Total missing & 0 & \#DIV/0! \\
\hline \multicolumn{3}{|l|}{ WD $2 \& 3$} \\
\hline Total Admissions & 0 & \#DIV/0! \\
\hline Inpatient service days & 0 & \#DIV/0! \\
\hline Total Discharges* & 0 & \#DIV/0! \\
\hline
\end{tabular}

Figure 7: Auto-generating sums and averages

\begin{tabular}{|l|c|c|c|}
\hline & PCU & $\mathbf{1}$ & 2 \& 3 \\
\hline Inpatient service days (for a period) & 0 & 0 & 0 \\
\hline Average Daily inpatient census & \#DIV/0! & \#DIV/0! & \#DIV/0! \\
\hline Average length of stay & \#DIV/0! & \#DIV/0! & \#DIV/0! \\
\hline Inpatient bed occupancy rate (\%) & \#DIV/0! & \#DIV/0! & \#DIV/0! \\
\hline Bed Turnover rate (\%) & \#DIV/0! & \#DIV/0! & \#DIV/0! \\
\hline & & & \\
\hline Death Rates(\%) & \#DIV/0! & \#DIV/0! & \#DIV/0! \\
\hline
\end{tabular}

Figure 8: Auto-generating key indicators

\section{Phase 3: Post Intervention Analysis}

\subsection{KIIs and the FGDs}

Post interventional KIIs and the FGDs were also analysed using the same framework used in the pre-interventional stage.

1. Not having to rewrite the 'patient summaries' gave sisters time to pay more attention to nursing care supervision.

2. The reporting formats were pronounced as being 'very easy, uniform and well organised'.

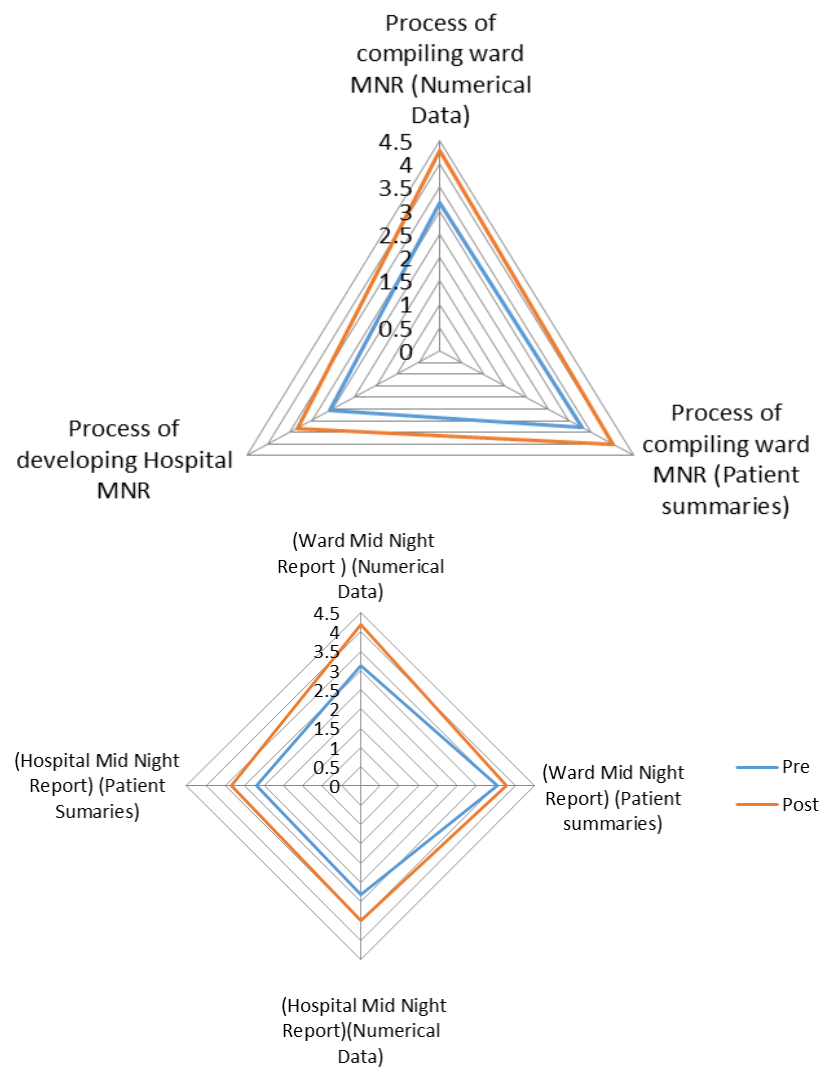

Figure 9: Participants' satisfaction towards data collecting/ reporting tools and data management process 
3. 'Patient Summaries' were well received by the administrators' this is what we wanted. Clear, short summaries'

4. Uniformity of MNRs and the similarity to the analysis sheet made the data entry process as 'very easy and fast'.

5. Satisfaction was expressed regarding error identification, data visualisation and the autogeneration of basic indicators. 'We don't have to do them manually; it is easy. Less errors'.

6. Graphs showing disease trends were stated as extremely useful. 'If a graph shows an increase, we can act early'.

7. Matrons used staff data to relocate nurses during the night shift according to the workload.

8. Provisions to identify errors were described as 'one of the best changes' and the collection of 'Same Day Discharges' allowed to 'show the entire workload done'.

Discussion of hospital statistics at the Management Committee Meetings and weekly summaries received by the RDHS office was perceived as extremely satisfying.

\subsection{Changes in selected indicators:}

Table 1 gives pre and post-intervention values of selected variables demonstrating the changes in data quality, dissemination and decision making.

\subsection{Results of the satisfaction survey:}

Results illustrated in Figure 9 demonstrate an increased level of satisfaction in the post interventional stage in all domains.

\section{DISCUSSION}

Introduction of automation has proven to be an effective method of enhancing data management process as demonstrated by many authors.
However, in Sri Lanka, the process has been slow and difficult. Many factors described in the literature, including the lack of funds, underdeveloped technology and human factors such as resistance to change and difficulties in adjusting to new technology may have stalled the process.

In this study, the satisfaction of those involved in the process showed an increase in multiple domains, as demonstrated by views expressed in KII and FGDs. Results of the satisfaction survey strengthen these views.

Pre and Post interventional stage results were compared, and an increase in data quality was evident. Errors were reduced by $77.78 \%$ during a period of one month. Previously unreported data were routinely reported with the new modifications. Data dissemination improved with more summary reports being delivered to the Regional Director of Health Services (Zero to five reports/ month). Increased use of data in resource allocation and identification of disease trends were also observed.

However, shortage of equipment and skilled human resources intended that the automation could only be introduced at a later stage in the process. It was this same realisation that made the project to adopt gradual modifications rather than a complete overhaul.

The possibility of using data for decision making was embraced by the participants, as was evident in the interviews. Data collectors and reporters showed higher satisfaction with the ability of the process to increase data quality.

However, there are many documented factors leading to difficulties in adopting evidence-based decision-making processes. The inherited differences in the nature of the decisions, allotting of higher value for experience, and selftaught knowledge to decision making are among them(10). These are likely to be prevalent among BHH managers. However, in contrast to what is described in the literature, top and middle-level managers in Sri Lanka has a medical or nursing background. This could have contributed to the

Table 1: Pre and post-intervention values of selected variables

\section{Variable}

Pre-Intervention

Number of 'Same Day Discharges' reported during one month

Number of erroneous Midnight Reports submitted during one month (Errors in the difference between calculated MNR and census results)

Number of summary reports sent to the RDHS during one month Number of management committee meetings where hospital data were discussed

\begin{tabular}{cc} 
None & 30 \\
9 & 2 \\
None & 5 \\
\hline $\begin{array}{c}\text { None (two meetings } \\
\text { considered) }\end{array}$ & 1
\end{tabular}


faster adoption of the modified system. As suggested by the World Health Organization (WHO), training and awareness programs may have also played a vital role in the change management process ${ }^{(11)}$.

\section{CONCLUSIONS}

Initially, the MNR compilation was time-consuming, and the reports contained many deficiencies. This project introduced a user-friendly intervention with the involvement of stakeholders which improved the data quality, staff satisfaction and promoted data dissemination and evidence-based decision making. The study recommends the continuous upgrading of the Midnight data management system at BH Horana with the revitalisation of the stalled automation process.

\section{REFERENCES}

1. The Rise of Big Data in Hospitals: Opportunities Behind the Phenomenon [Internet]. [cited 2019 Jan 12]. Available from: https://www.beckershospital review.com/healthcare-information-technology/the -rise-of-big-data-in-hospitals-opportunities-behindthe-phenomenon.html

2. Toolkit on monitoring health systems strengthening: Health Information Systems [Internet]. World Health Organization; 2010 [cited 2019 Feb 12]. Available from: https://www.who.int/healthinfo/statistics /toolkit_hss/EN_PDF_Toolkit_HSS_InformationSyste ms.pdf

3. Office USGA. Medical ADP Systems: Automated Medical Records Hold Promise to Improve Patient Care [Internet]. 1991 [cited 2018 Dec 17]. Available from: https://www.gao.gov/products/IMTEC-91-5

4. Balaraman P, Kosalram K. E -Hospital Management \& Hospital Information Systems - Changing Trends. IJIEEB. 2013 May 1;5(1):50-8.

5. Pole D. Electronic Patient Records in Sri Lankan Hospitals. Sri Lanka Journal of Bio-Medical Informatics. 2010 Jan 5;1(1):43-5.

6. National eHealth Guidelines and Standards [Internet]. Ministry of Health, Nutrition and Indigenous Medicine; 2016 [cited 2019 Feb 16]. Available from: http://www.health.gov.lk/enWeb /publication/NeGS_v_1.pdf

7. MS BH Horana. Information Management System, BH Horana. 2018.

8. Gale NK, Heath G, Cameron E, Rashid S, Redwood S. Using the framework method for the analysis of qualitative data in multi-disciplinary health research. BMC Medical Research Methodology. 2013 Sep 18;13(1):117.
9. Bowen G. Document Analysis as a Qualitative Research Method. Qualitative Research Journal. 2009 Aug 3;9:27-40.

10. Walshe K, Rundall TG. Evidence-based Management: From Theory to Practice in Health Care. The Milbank Quarterly. 2001 Sep;79(3):429-57.

11. World Health Organization. Health Work Force: Education and Training [Internet]. World Health Organization. World Health Organization; 2019 [cited 2019 Jun 30]. Available from: http://www.who.int /hrh/education/en/ 